\title{
INTELLIGENT HOME ENERGY MANAGEMENT SYSTEM INCLUDING RENEWABLE ENERGY BASED ON MICAZ'S
}

\author{
Archana.S.Kokatanur' ${ }^{1}$, Susham.K.Rao ${ }^{2}$ \\ ${ }^{1}$ M. Tech Student, Dept.ECE, AMC Engineering College, Bangalore, Karnataka, India \\ ${ }^{2}$ Assistant Professor, Dept.ECE, AMC Engineering College, Bangalore, Karnataka, India
}

\begin{abstract}
As the numbers of large-sized electric home appliances are increasing, the home energy consumption is also increasing proportionally. To reduce the home energy cost, it is necessary to consider both energy consumption and generation. In this application intelligent home uses renewable energies. The problems of home energy management systems are solved by implementing energy saving method and renewable energy sources. Energy sources are connected to the grid via battery and inverter, the output of battery is connected to microcontroller. For displaying the battery voltage and availability of energy source microcontroller is connected to LCD. Some units will be consumed whenever load is connected, consumed units will be calculated with the help of microcontroller and it is displayed on the LCD.
\end{abstract}

Keywords: Home Energy Management System, ZigBee, Renewable Energy, Power Line Communication, Microcontroller, Inverter.

\section{INTRODUCTION:}

Now a days in home areas world most considerable topic is energy saving and generation of power by smart home energy management system by using solar panel and wind turbine. Usage of wireless devices is increasing day by day so this application helps us to know the energy consumption and generation.

Energy management systems can be used to control devices like lighting systems and High Voltage Alternating Current units across multiple locations, such as office buildings, grocery, retail, restaurants sites.

Energy management systems also provide metering and monitoring functions, which allows them to take decisions regarding energy activities across their sites.

Energy management includes planning and energy related production and consumption units.

\subsection{Existing System}

Architecture of Home Energy Management System

\section{Including Renewable Energy}

A home has two parts concerning energy:

consumption and generation. Numerous home appliances and lights are in the energy consumption part.

Renewable energies such as solar and wind energies are in the energy generation part. Because a home consumes and generates energy, a control device like a home server needs to monitor and control both energy consumption and energy generation to minimize the energy cost. Fig. 1 shows the system architecture of smart HEMS that considers energyconsuming home appliances and lights and energygenerating solar and wind energy resources.

In the section of energy consumption, the energy consumed by home appliances and lights is monitored through an energy measurement and communication unit (EMCU) that is installed in each outlet and each light. The EMCU will measure the energy and power consumption of home appliances and lights.

\subsection{Proposed system}

\subsubsection{System Architecture}

Although numerous efforts are taken for home energy management systems, still energy management can achieve more energy-efficient home than before.

A new architecture for energy efficient home is proposed here. In the energy generation part we will add more natural power generators: With solar and wind energy we will also add tiles energy, garbage and mechanical power generators. By adding these renewable energy sources one can reduce the cost of electricity. The proposed renewable energy sources are eco- friendly and they are very cost effective. The tiles energy is produced by unique tiles which are made up of recycled materials. And also the tiles energy does not contain any toxic chemicals as in batteries. The tiles energy will be best suited in areas where more footsteps fall. Most garbage finds their way to water or land without proper treatment, due to which environment pollution is increasing. By using garbage energy one can avoid the water pollution and air pollution. 
Power saving technique: Home appliance like geyser/fridge/AC/FAN is automatically controlled. In this module along with controlling the home appliances, the power consumption is also controlled as per usage.

For example: At home as we switch ON the geyser for number of times, it will make water hotter than our requirements. So this leads to wastage of power, in this format load/geyser will switch OFF once the set temperature of water is heated. By this method we can save the power consumption.

\section{ARCHITECTURE:}

\subsection{Transmitter Block Diagram}

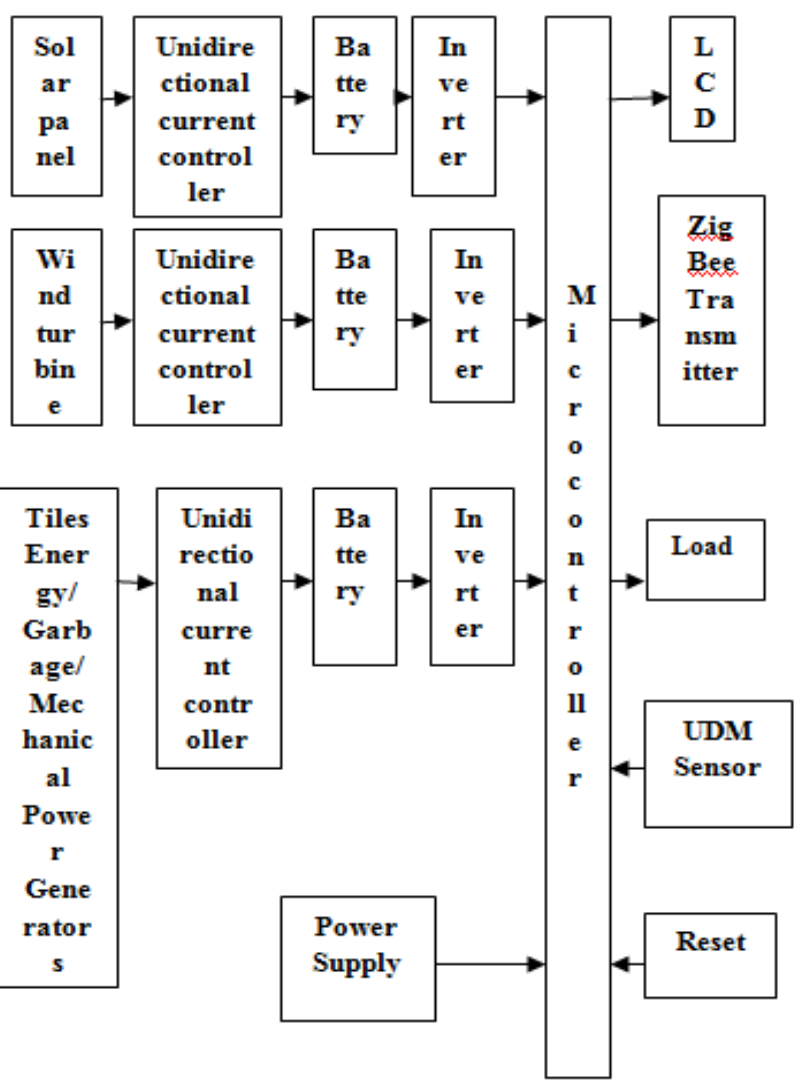

\subsection{Receiver Block Diagram}

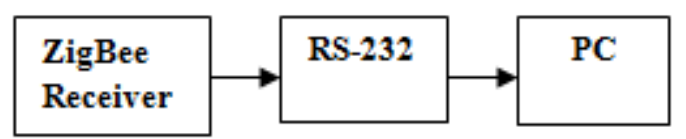

Solar Panel: Solar panel is a device made up of photo voltaic cells. This device converts source of light available from the sun into electricity. By using Maximum Power Point Tracking using two LDR and a DC motor power generation can be increased.

Wind turbine: Wind turbine is wind driven turbine, which converts kinetic energy from wind into electricity.

Battery: To store the power from solar panel and wind turbine the $12 \mathrm{v}$ battery is used.
Inverter: Inverter is used to convert the supply from $12 \mathrm{v}$ to $230 \mathrm{v}$ for providing the home appliances from renewable sources.

ZigBee: ZigBee is wireless device used for transmitting and receiving purpose. Its range is $100 \mathrm{~m}$.

LCD: Liquid crystal display is electronic display panel comprising molecules of liquid crystals which consists the light modulating properties.

UDM sensor: Ultrasonic Distance Measure sensor is small, light weighted distance measuring device. It is easy to set up and is compatible with all cameras and lenses. UDM measures the distance between sensor plane and objects by sending ultrasonic pulses and measuring the time taken to bounce back. UDM sensor has stable, non-contact, precise and accurate distance measurement from about $2 \mathrm{~cm}$ to 4 meter.

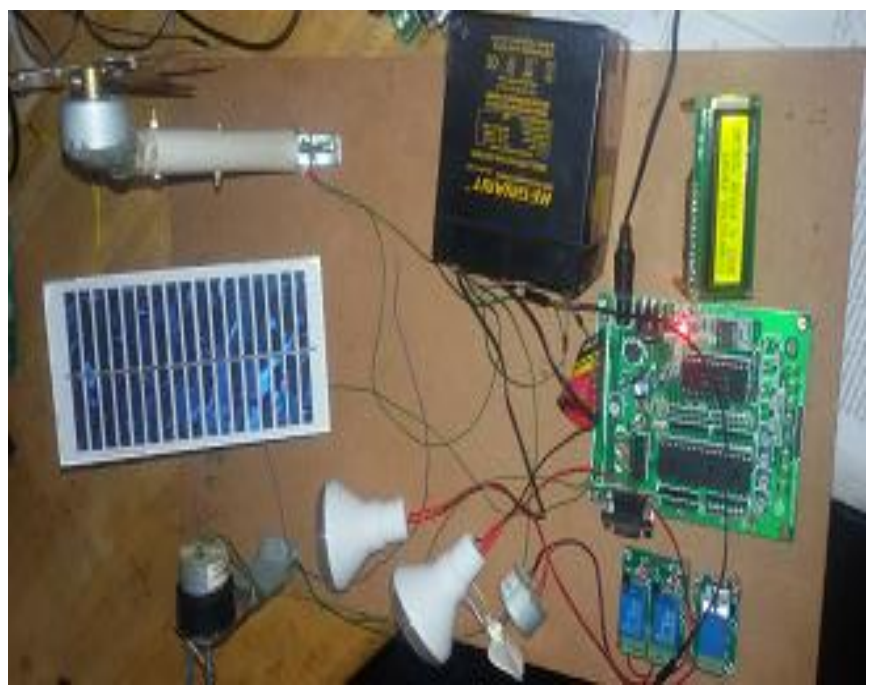

Fig -1: prototype set up

\section{Hardware Used:}

- Microcontroller

- Zigbee

- Battery

- Power supply

- RS232

- LCD

- Inverter

\section{Software Used:}

- $\quad$ KEIL software

- $\quad$ embedded C

\section{Applications}

- $\quad$ Energy cost can be reduced

- Increase the power generation

- $\quad$ Energy Monitoring

- Know the cost of energy usage 


\section{CONCLUSION}

The intelligent home energy management system works well in real time. Solar energy and wind energy are tremendously available in nature, so there is enough production of power to supply the home appliances. The cost of the implementation is low and also the system reduces the cost of the power. To save the energy for upcoming future generations, home appliances are kept off during peak hour to maintain energy management.

\section{REFERENCES:}

[1]. Jinsoo Han, Chang-Sic Choi, Wan-Ki Park, Ilwoo Lee, and Sang-Ha Kim, "Smart home energy management system including renewable energy based on ZigBee and PLC," in Proc. IEEE International Conference on Consumer Electronics, Las Vegas, USA, pp. 544-545, Jan 2014.

[2]. Hyunho Park and Hyeong Ho Lee, "Smart WLAN discovery for power saving of dual-mode terminals," ETRI Journal, vol.35, no.6, pp.1144- 1147, Dec. 2013.

[3]. Hayato Yamauchi,Kosuke uchida and Tomonobu Senjyu, "Advanced Smart home,"in Proc.IEEE Intern Sarah Darby, "The Effectiveness of Feedback on Energy Consumption," Environmental Change Institute, Univ. of Oxford, Apr. 2006.

[4]. Young-Sung Son and Kyeong-Deok Moon, "Home energy management system based on power line communication,"in Proc.IEEE Trans.Consumer Electron.,vol. 56, no. 3, pp.1380-1386, Aug. 2010

[5]. Hyoungsik Nam and Hoon Jeong, "Data supply voltage reduction scheme for low-power AMOLED displays," ETRI Journal,vol.34,no.5,pp.727-733,oct.2012.

[6]. Young-Sung Son and Kyeong-Deok Moon, "Home energy management system based on power line communication,"'in Proc.IEEE International Conference on Consumer Electronics,Las Vegas,USA,pp,115-116,Jan.20

[7]. Saeed Jahdi and Loi Lei Lai, "Grid integration of windsolar hybrid renewable using AC/DC converters as DG power sources,"in Proc.World Congress Sustainable Technologies,London,UK,pp.171-177,Nov.2011.

[8]. Chia-Hung Lein,Hsien-Chung Chen,Ying-Wen Bai,and Ming-Bo Lin, "Power monitoring and control for electric home appliances based on power line communication,"in Proc.IEEE International Instrumentation and Measurement Technology Coference,British Columbia,Canada,pp.21792184,May 2008.

[9]. Sunngjin Park, Eun Ju Lee,Jae Hong Ryu,Seong-Soon Joo, and Hyung Seok Kim, "Distributed Borrowing Addressing Scheme for ZigBee/IEEE 802.15.4Wireless Sensor Networks,"ETRI Journal,vol.31,no.5

[10]. Tsuyoshi Ueno, Ryo Inada,Osamu Saeki, and Kiichiro Tsuji, "Effectiveness of Displaying Energy Consumption Data in Residential Houses-Analysis on How the Residents act in response" Proceedings of ECEEE 2005 Summer Study,2005.

\section{BIOGRPHIES}

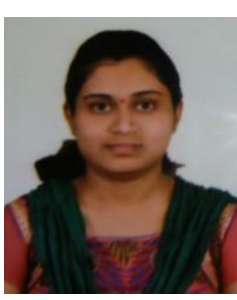

Archana.S.Kokatanur is currently pursuing her Master's degree in branch VLSI Design and Embedded Systems in AMC Engineering College, Bangalore. She received the Bachelor's Degree in Electronics and Communications Engineering from Navodaya Institute of Technology, Raichur affiliated to the Visvesvaraya Technological University(VTU), Belgaum.

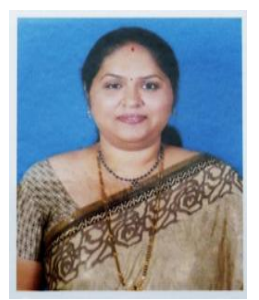

Susham K Rao is currently working as Assistant Professor in AMC Engineering College, Bangalore in Dept. of Electronics \&Communication Engineering. She had received Master's degree in branch VLSI and Embedded Systems from Reva Institute of Technology(RITM),Bangalore and Bachelor's degree from KVG Engineering College, Sullia. She has seven years of experience which include Industry and Teaching. Her area of interests are VLSI, Digital Signal Processing, Embedded Systems, etc 